Revista de la red interuniversitaria de estudios sobre las literaturas rioplatenses contemporáneas en Francia

19 | 2018

La rebelión de los hijos: el judaísmo en la literatura latinoamericana contemporánea entre tradición y asimilación

\title{
El judaísmo, una tradición rebelde
}

\section{David Lemler}

Traductor. Valentina Litvan

\section{OpenEdition}

\section{Journals}

Edición electrónica

URL: http://journals.openedition.org/lirico/6842

DOI: $10.4000 /$ lirico.6842

ISSN: 2262-8339

\section{Editor}

Réseau interuniversitaire d'étude des littératures contemporaines du Río de la Plata

\section{Referencia electrónica}

David Lemler, «El judaísmo, una tradición rebelde », Cuadernos LIRICO [En línea], 19 | 2018, Puesto en línea el 20 enero 2019, consultado el 20 abril 2019. URL : http://journals.openedition.org/lirico/6842 DOI : $10.4000 /$ lirico.6842

Este documento fue generado automáticamente el 20 abril 2019.

\section{cc) $(1) \subseteq$}

Cuadernos LIRICO está distribuido bajo una Licencia Creative Commons Atribución-NoComercialSinDerivar 4.0 Internacional. 


\title{
El judaísmo, una tradición rebelde
}

\author{
David Lemler
}

Tradución : Valentina Litvan

\section{NOTA DEL EDITOR}

En nombre de Cuadernos LIRICO agradecemos al autor por su texto "Le judaïsme, une tradition rebelle", escrito especialmente para este número y que aquí traducimos.

1 "La rebelión de los hijos, ese tema tan común en la literatura de principios del siglo [xx], ha alcanzado en el microcosmos familiar judío la dimensión de una verdadera inversión de valores". El sintagma "rebelión de los hijos", que emplea Stéphane Mosès acerca de la revuelta de determinados jóvenes intelectuales judíos contra sus padres asimilacionistas en la Alemania de principios del siglo XX, resuena como un eco de la figura bíblica del "hijo obstinado y rebelde". Pero el hijo rebelde del siglo XX es el reflejo invertido del hijo rebelde del Deuteronomio, ya que, como veremos, desde la interpretación rabínica, este último se vuelve contra una figura paterna que ya no asume su rol de transmisor de la enseñanza de la Torá.

2 Esta rebelión halla su expresión más cruda y brutal en la Carta al padre de Franz Kafka, donde el hijo expone al padre a su propia inconsistencia: la que se manifiesta cuando reprocha al hijo no reproducir el "fantasma del judaísmo" que él mismo se complace en practicar. Este padre, portador de un orden simbólico culpabilizador y fantasmagórico, anuncia la figura de una ley impenetrable que condena al sujeto a morir bajo el umbral de sus puertas, parábola con la que termina $E l$ proceso. Frente a este callejón sin salida kafkiano, propondremos aquí otras opciones de la rebelión contra los padres, que implicarán o no la reivindicación de una apropiación de la tradición judía, tal y como lo ilustran los autores estudiados por Mosès. Franz Rosenzweig encuentra en el judaísmo el recurso para un "pensamiento nuevo" que ha de superar lo que él percibe como los escollos del idealismo alemán. Gershom Scholem, volcándose hacia la Cábala con las 
herramientas modernas de la filología, entiende que para revivificar el judaísmo moribundo de la modernidad se ha de dar acceso a la tradición mística que, según él, lo habría animado secretamente a lo largo de los siglos. Walter Benjamin, por su parte, retoma de manera menos evidente nociones centrales de la tradición judía en el marco de su propia filosofía mesiánica de la historia.

3 En este proceso parece emerger una extraña dialéctica mediante la cual la rebelión se apodera del objeto que representa la autoridad perdida del padre, la tradición de la que supuestamente este debería constituir un eslabón. Los hijos no se rebelan contra un orden antiguo, sino, al contrario, contra el hecho de que ese orden antiguo, que las familias que se consideran "judías" han mantenido formal o nominalmente, haya perdido todo significado. Los hijos se sublevan contra una forma de indiferencia de los padres ante el judaísmo, contra lo que podríamos llamar su ausencia de rebelión, de cuestionamiento o de puesta en duda ante el compromiso que implica la identidad judía, contra el aburguesamiento de un judaísmo que funciona como mero marcador social sin ninguna referencia a la tradición del estudio. La rebelión alcanza entonces diversas formas de "retorno" a la tradición. Esta paradoja, que aparece en un momento de la historia del judaísmo moderno, refleja una tensión entre tradición y rebelión que de hecho es inherente a la propia tradición judía.

4 Tradición y rebelión son sin duda dos términos antagónicos. Mientras la tradición transmite al presente un pasado bajo la figura de un "eterno ayer" (según la expresión de Max Weber) que no se puede enmendar, la rebelión, en cambio, quiebra la evidencia de un orden establecido y deja entrever otra posibilidad. Sin embargo, la tradición rabínica implica en sí misma una articulación fecunda de la instauración y conservación de un orden que, a falta de algo mejor, calificaremos por un lado de "religioso" y, por otro, de rechazo de todo orden religioso. Esto es así porque se trata de una tradición que permite que se construya una herencia en la separación.

5 En efecto, los dos grandes fundadores del pueblo judío, Abraham y Moisés, son rebeldes que rompen con el orden opresivo establecido. El gesto abrahámico de ruptura frente a la idolatría es reconducido más tarde a escala colectiva con la liberación de Egipto. La fidelidad que supone la alianza entre Dios y los hombres implica, desde la Fundación abrahámica, una separación respecto del común de la humanidad y de sus formas más habituales de organización. Ahora bien, la fidelidad respecto a esta separación o liberación se presenta paradójicamente como una sumisión a un Dios y a su ley. El vocablo avoda, el "culto", designa asimismo el trabajo servil. Según un midrash (interpretación rabínica), el término Anokhi (Yo soy) con el que Dios inaugura los Diez Mandamientos, presentándose como el que libera de la casa de la esclavitud (Ex 20,2), resulta ser un término tomado de la lengua egipcia. El pueblo de los antiguos esclavos recién emancipados, que sólo comprendía la lengua de la opresión, tendrá que subvertirla.

6 En el seno de una tradición que conlleva un proyecto de emancipación, esta dialéctica entre la rebelión y la sumisión aparece de manera ejemplar en la presentación que ofrece Maimónides, en el siglo XII, de la genealogía de la idolatría y del judaísmo. La idolatría se inaugura por un error, no sobre el número de dioses, ni sobre la naturaleza del dios único, sino sobre el modo de servirlo. El error consistió, fundamentalmente, en querer establecer la relación con Dios a través de un culto; un error que se remonta al origen de 
la humanidad, a la época de Enoc, el nieto de Adán. Según un midrash (Bereshit Rabba, 23, 7), cuando el versículo enuncia "que entonces comenzaron (huhal) a invocar el nombre de YHWH" (Gn 4, 26), hay que entender que se dedicaron a profanarlo: la raíz hebraica ḥll puede significar tanto comenzar como profanar. Esta lectura contra-intuitiva del versículo permite percibir la tensión constitutiva de todo culto religioso. En tanto medio por el que el ser humano (esta bien podría ser la traducción del nombre de Enoc) busca instituir una relación con lo divino, conferirle una existencia y una presencia en su mundo, el culto religioso implica la cosificación y la fetichización. El orden religioso es fundamentalmente idólatra.

7 En la genealogía de Maimónides, el tiempo da sus frutos. Enoc, en su intento de alabar al dios único, genera, en etapas sucesivas, una multiplicación de los intermediarios entre los hombres y dios -intermediarios tanto materiales (astros, templos y estatuas) como sociales (profetas y sacerdotes). El resultado es un culto religioso que organiza al conjunto de la sociedad humana, sometiendo a los hombres a unas exigencias desmesuradas, pero olvidándose del objetivo primero: crear un vínculo entre los humanos y el dios inaccesible del monoteísmo. Abraham habría sido, según Maimónides, quien en el seno de una humanidad idólatra, habría redescubierto, exclusivamente gracias a su inteligencia, la existencia del dios único, Dios que por lo mismo lo conducirá a separarse de forma violenta de la sumisión a los ídolos de las realidades mundanas. La humanidad postabrahámica corre el riesgo de recaer en sus errores anteriores. Con el tiempo, los hombres vuelven a caer en la idolatría e incluso los israelitas, cuando se encuentran esclavizados en el Egipto faraónico, están dispuestos a olvidar la enseñanza de Abraham de la que son depositarios.

8 Bajo esta perspectiva, la Torá es una ley religiosa paradójica pues recoge la pulsión demasiado humana de religión al mismo tiempo que, en la medida de lo posible, advierte a los humanos contra la deriva idólatra intrínseca a toda organización religiosa. El judaísmo construye un orden religioso y las correspondientes autoridades para perpetuarlo, basándose en el rechazo radical del orden religioso visto como esencialmente perverso y opresivo. El tipo de autoridad así constituida, que garantiza la fidelidad a la rebelión contra las autoridades teológico-políticas, será -como se puede imaginar- de una naturaleza singular.

9 En el seno del judaísmo rabínico, la fuente de la autoridad es la inteligencia hermenéutica, inteligencia del texto asociada a la inteligencia de la existencia. El axioma de la tradición rabínica es la existencia de una Torá oral. Considerada como "entregada" en el Sinaí al mismo tiempo que la Torá escrita, su pleno desarrollo se inicia a partir de la retirada de la presencia divina, con el final de la profecía en el momento del regreso del exilio babilónico, pero sobre todo con la destrucción del Segundo Templo en 70 d.C. La autoridad detentada por los reyes, los sacerdotes y los profetas pasa entonces a estar en manos de los "sabios". El carácter hereditario y la inspiración ceden su lugar a la inteligencia humana, la única capaz de acceder a la ley divina. Esta misma no podría ser una ley liberadora si se sometiera arbitrariamente a unos decretos caprichosos. Sólo puede serlo inscribiendo a quien se somete a ella en el horizonte de un sentido que tiene que irse construyendo individual y colectivamente con la comunidad de quienes son depositarios de esta "herencia" (Dt 33, 4). Concebida de este modo, la Torá oral no es una 
"tradición de interpretación" en el sentido de un corpus de exégesis que se transmitiría. Se trata más bien de una operación por la cual la Torá escrita se somete a la comprensión inteligente de sus intérpretes.

10 Existe en el Talmud una querella hermenéutica que ilustra el carácter subversivo de esta operación. Uno de los axiomas de lectura de los rabinos es que cada elemento del texto bíblico es instructivo, incluso las expresiones redundantes o los términos desprovistos de significado propio. Entre esos términos, encontramos la partícula 'et, muy frecuente en hebreo bíblico. Ésta, por regla general, sólo tiene una función gramatical -introducir el complemento de objeto directo definido de un verbo-, pero otras veces este término significa "con". En el Talmud se explica en varias ocasiones que un maestro, Rabbi Shimeon ha-Amsuni (siglo II), queriendo conferir un máximo de significado al texto bíblico, tenía la costumbre de traducir todas las partículas 'et por "con", lo que implicaba suponer en numerosos versículos bíblicos un término implícito que el texto habría silenciado. Del mismo modo ocurriría con el versículo "honra a tu padre y a tu madre": si se traducen por "con" las dos partículas 'et que contiene el texto hebreo, se lee "honra con tu padre y con tu madre". Queda por saber a quién le convendría honrar "con su padre" y "con su madre". Los Sabios están de acuerdo en decir que la partícula 'et nos enseña que conviene honrar "con su padre" a la mujer de su padre, "con su madre" al marido de su madre.

11 Pero, frente al versículo “('et) A Adonai tu Dios, temerás” (Dt 10, 20), Rabbi Shimeon haAmsuni decidió renunciar a toda interpretación del término 'et. De otro modo supondría asociar a Dios con otro ser a quien convendría temer, y pondría en duda la unicidad de Dios y su soberanía única y exclusiva. Descubre así que la libertad del intérprete que se esfuerza en volver al texto más significativo de lo que ya es según las reglas habituales de la lengua, amenaza con conducir a la ruina la propia autoridad de la ley divina. En este contexto interviene Rabbi Akiva, una de las más importantes figuras de la tradición rabínica del siglo II, y zanja la cuestión: la partícula 'et incluye a los "discípulos de los Sabios". Junto a Adonai, el Eterno, hay que temer a los maestros de la tradición rabínica. Mediante un golpe de increíble audacia, Rabbi Akiva afirma que el verdadero temor a Dios sólo es accesible a través de la enseñanza de los rabinos. La ley divina sólo tiene autoridad mediante la lectura inteligente de los que buscan conferirle un significado máximo.

12 El gesto es sin duda ambiguo: ¿quién podrá decidir quién es "inteligente”? La tradición rabínica delimita los muros de la casa de estudio, decidiendo quién es susceptible de entrar en ella. Pero, entre esos muros, instaura un espacio de discusión, para someter el sentido del texto bíblico a la inteligencia humana, un sentido que por tanto se afirma plural (dos opiniones contrarias constituyen "una y otra palabras del Dios vivo") y susceptible de ser renovado.

13 De este modo, la Torá organiza la fidelidad a la rebelión contra el fetichismo idolatra a través de la afirmación de un sentido que hay que conquistar por la inteligencia. Sabemos sin embargo que junto a la orden del estudio que instaura una relación siempre singular con la ley, el judaísmo se organiza en una comunidad regida por una ley religiosa colectiva. Uno de los objetos privilegiados del estudio es entonces el detalle sobre la modalidad de aplicación de la ley, y uno de sus efectos es la halakha, la producción de normas pretendidamente válidas para el conjunto de la comunidad. Durante mucho 
tiempo, el judaísmo fue provisto de una alta jurisdicción, el gran Sanedrín, tribunal compuesto por setenta y un miembros que, en los casos difíciles o nuevos, estaba habilitado para zanjar por mayoría las cuestiones de la halakha. El Talmud está dominado por el temor de una desunión del pueblo judío, por la multiplicación de disensiones jurídicas. El hecho de que el imperativo de una subjetivación de la Torá por el estudio se asocie al de la conformación a la halakha común constituye una de las paradojas que estructuran el judaísmo rabínico. Así como el primero instaura un tipo específico de autoridad en la ley divina, guardando la memoria del gesto abrahámico cuando rechaza la sumisión a un sistema de normas desprovistas de sentido, el segundo, por su parte, aparenta, al menos formalmente, la instauración de un sistema semejante. Parece ser necesario un colectivo regido por la halakha para que pueda advenir la relación crítica ante la ley que se inventa a través del estudio. La unidad de Israel que la halakha y en ú ltimo término la autoridad del Sanedrín busca asegurar, pretende garantizar así la permanencia en el tiempo del carácter colectivo surgido de la rebelión abrahámica y mosaica, tal y como se manifiesta a través del modo en el que la tradición trata a quienes se oponen a sus propias autoridades.

14 Si por un lado las autoridades rabínicas son autoridades paradójicas por el hecho de fundarse en gestos de rebelión, por otro lado, la rebelión contra estas autoridades constituye en sí mismo un gesto paradójico. De este gesto, la tradición rabínica propone dos figuras, el "anciano venerable e insumiso" (zaqen mamre) y el "hijo testarudo y rebelde" (ben sorer u-moreh).

15 En el primer caso, se trata de un sabio, con la sabiduría, las competencias y las características necesarias para integrar el Gran Sanedrín, pero que se opone públicamente a su autoridad. Frente a las autoridades jurídicas establecidas, hace valer una comprensión disonante en alguna cuestión de halakha, reivindicando formar parte de una tradición que le vendría de sus maestros o de su propia inteligencia de la ley. Opone esta opinión discordante al tribunal local, que hace remontar el asunto a los tribunales superiores hasta el mismísimo Gran Sanedrín. Si el Sanedrín no le da la razón, el sabio debe conformarse a la halakha común. Entonces interviene la distinción crucial entre el plan del estudio y la elaboración subjetiva de la ley y el de su aplicación colectiva: en el marco del estudio de la Torá, se autoriza al sabio que siga enseñando su punto de vista, pero a nivel de su aplicación, pues debe actuar y prescribir a sus discípulos que actúen conforme a la posición del Sanedrín. Si actúa o prescribe según su propia comprensión, contra la opinión del Sanedrín, podrá ser sancionado con la pena capital. Delitos de lesa majestad, se dirá: el Sanedrín se comporta como una autoridad tiránica a la que no es posible oponerse. En realidad, al reivindicar una mejor comprensión de la Torá, el anciano venerable e insumiso se encuentra ante una puesta a prueba frente a las autoridades de su tiempo. Desestimado, mantiene su posición, sin distinguir el plan del estudio del de la aplicación de la ley. Al hacer esto amenaza la unidad de Israel y, a través de ella, la permanencia de un sustrato político en el seno del cual la elaboración singular de la ley siga siendo posible.

16 La figura simétrica del "hijo testarudo y rebelde" está descrita en cuatro versículos lapidarios (Dt 21, 18-21). Un hijo que no escuchara la voz de su padre y de su madre podría ser llevado por ellos delante de un tribunal para ser sancionado y condenado a muerte en caso de reincidencia. Este derecho sobre la vida y la muerte del hijo que la Biblia parece otorgar a los padres se convierte dentro de la tradición rabínica en un modelo teórico para pensar lo que hoy llamaríamos la adolescencia, el momento del paso de la infancia a 
la edad adulta. Los Sabios multiplican los criterios necesarios para condenar a un hijo testarudo y rebelde, de modo que el Talmud enuncia que "nunca nadie ha sido declarado hijo testarudo y rebelde y [que] nunca nadie lo será", de modo que el único propósito del caso descrito en la Biblia consiste en elevarlo a objeto de estudio. Se trata, efectivamente, de estudio, puesto que el hijo testarudo y rebelde putativo sería condenado precisamente por substituir la obligación del estudio con la satisfacción de su deseo narcisista. En lugar de "escuchar la voz de sus padres", es "glotón y borracho" según la expresión del versículo (Dt 21, 20). Según los Sabios, esto significa que para ser condenado, debería, a lo largo de su pubertad, haber robado dos veces el dinero de sus padres para comprarse carne y vino antes de consumirlos cual bandido que se abalanza ante un botín. Mediante el dinero, el hijo se ampara en el deseo de sus padres, de su "voz" como un eco lejano oído en el Sinaí, y la transforma en objeto de placer, representado por la carne y el vino. El hijo se ve así condenado a causa del tipo de subjetividad que manifiesta con este ágape en busca de una satisfacción inmediata, sin resto -una subjetividad fundada en el rechazo del estudio paciente, del compromiso con la construcción de un sentido y en la exigencia de justicia. El anciano venerable e insumiso rechaza la ley en nombre del estudio de la que ésta es soporte, el hijo testarudo y rebelde no se percata de que la ley es el soporte de un estudio. Para él no es más que una instancia autoritaria y violenta a la que se opone, mediante un violento fuera de la ley (se supone en efecto que su voracidad lo condena a convertirse en un ladrón y un asesino).

Los hijos rebeldes de la modernidad -como anunciamos al principio- parecen estar en una situación inversa a la del hijo rebelde de la Biblia. No se trata de que no escuchen la voz de sus padres, sino de que sus padres se han vuelto mudos, al menos en materia de Torá. Desde el fondo de este silencio, hay quienes quieren encontrar una voz inventando la suya a la manera de los pensadores judíos alemanes de Mosès. Queda por preguntarse en qué medida este silencio también ha suscitado la vocación de algunos hijos rebeldes entre los escritores judíos latinoamericanos.

\section{AUTORES}

\section{DAVID LEMLER}

Université de Strasbourg 